\title{
Atmospheric patterns for heavy rain events in the Balearic Islands
}

\author{
A. Lana, J. Campins, A. Genovés, and A. Jansà \\ Centre Meteorològic de les Illes Balears, Instituto Nacional de Meteorología, Spain \\ Received: 27 February 2007 - Revised: 18 April 2007 - Accepted: 13 May 2007 - Published: 28 June 2007
}

\begin{abstract}
The Balearic Islands, as well as other Mediterranean regions, are occasionally affected by heavy rain events, which can produce numerous damages. This study contributes to improve the understanding of the dynamical mechanisms that produce heavy rain events by means of a classification of their related atmospheric patterns.

Heavy rainfall dataset for the Balearic Islands and some gridded atmospheric parameters, derived from the HIRLAMINM- $0.5^{\circ}$ analyses, were the data used in this study. Heavy rain events were recorded at a set of pluviometric stations along the Balearics for a period of 9 years, from June 1995 to May 2004. The $1000 \mathrm{hPa}$ and $500 \mathrm{hPa}$ geopotential heights (hereafter $\phi_{1000}$ and $\phi_{500}$ ), as well as the $850 \mathrm{hPa}$ temperature $\left(T_{850}\right)$ were the fields utilized in the classification.

By means of a principal components analysis (PCA) the number of variables was reduced. The cluster analysis (CA) was then applied on those new variables and eight atmospheric patterns were finally obtained. Most of the patterns showed a strong relationship between heavy rain events and cyclones.
\end{abstract}

\section{Introduction}

The Western Mediterranean countries are affected by episodic severe weather phenomena, like heavy rain events (HR, hereafter), that usually produce numerous damages and, consequently, a strong economical and social impact in the area.

In the particular case of the Balearic Islands, the presence of a cyclone related to the heavy rain events has been observed in previous works by different authors, like Campins et al. (2006a), Jansà et al. (2000) and Romero et al. (1999), and it is on the basis of the MEDEX project. The MEDEX

Correspondence to: A. Lana

(lana@cmima.csic.es) project has the objective of improving the knowledge and the forecasting of the cyclones that produce high impact in the Mediterranean weather, focusing especially on heavy rains and strong winds (see http://medex.inm.uib.es).

The present study is an attempt to improve the understanding of the dynamical mechanisms that produce these phenomena, from a statistical point of view. The objective is to obtain the atmospheric patterns (hereafter, AP) that produce heavy rain events in the Balearic Islands. Some previous studies that analysed the synoptic atmospheric patterns related to extreme precipitation in other Mediterranean areas can be found in Houssos and Bartzokas (2006) and Romero et al. (1999).

\section{Data and methodology}

According to the data included in the MEDEX database and for the purpose of this study, a heavy rain event is defined as one that produces at least $60 \mathrm{~mm}$ of rain in $24 \mathrm{~h}$, at least in one pluviometric station. This threshold is similar to that used in other previous works (Jansà et al., 2001).

This study is a continuation of that of Campins et al. (2006a) whose main objective was to demonstrate the relationship between heavy rain and strong wind events in the Balearics and the presence of a cyclone in the area. As it is explained in Campins et al. (2006a), the rainfall data used in this study were registered between June 1995 and May 2004 at 216 pluviometric stations placed at the Balearics. 157 events of heavy rain were registered throughout these 9 years. This implies an average of 17.4 events per year (see Table 1 from Campins et al., 2006a), in which 8.6 events were noted in autumn $(\approx 50 \%)$. In 135 events of the $157 \mathrm{HR}$ events $(\approx 87 \%)$ a cyclone center was detected within a radius of $600 \mathrm{~km}$ around the Islands. Furthermore, the location of the cyclone center allowed the feeding of warm air to the HR affected area (for further details see Campins et al., 2006a).

Published by Copernicus Publications on behalf of the European Geosciences Union. 
Table 1. Number of HR events per season for each AP and for the total set of events.

\begin{tabular}{cccccc}
\hline AP & Spring & Summer & Autum & Winter & TOTAL \\
\hline AP1 & 7 & 2 & 8 & 3 & 20 \\
AP2 & 0 & 13 & 11 & 2 & 26 \\
AP3 & 4 & 2 & 6 & 3 & 15 \\
AP4 & 2 & 1 & 12 & 6 & 21 \\
AP5 & 0 & 1 & 6 & 5 & 12 \\
AP6 & 2 & 4 & 17 & 2 & 25 \\
AP7 & 3 & 0 & 10 & 6 & 19 \\
AP8 & 9 & 0 & 7 & 3 & 19 \\
TOTAL & 27 & 23 & 77 & 30 & 157 \\
\hline
\end{tabular}

In order to obtain the atmospheric patterns, smoothed gridded data from the High Resolution Limited Area Model from the Instituto Nacional de Meteorología, with a $0.5^{\circ}$ latitudelongitude resolution (HIRLAM-INM- $0.5^{\circ}$ ), were used. The study area comprised the domain from $33.5^{\circ} \mathrm{N}$ to $45.5^{\circ} \mathrm{N}$, and from $6^{\circ} \mathrm{W}$ to $11^{\circ} \mathrm{E}$. This placed the Balearics at the center of the study area, and took into account a great part of the Western Mediterranean Sea that affects the meteorological conditions of the islands, as the Gulf of Genoa and the coast that surrounds the islands.

For each HR event, the value of $\phi_{1000}, \phi_{500}$ and $T_{850}$ at the 875 grid points belonging to the area described above, were considered to be relevant in the heavy rain generation. HIRLAM-INM- $0.5^{\circ}$ analyses are available four times in a day (at 00:00, 06:00, 12:00 and 18:00 UTC), whereas rainfall data matched for a $24 \mathrm{~h}$ period, between 07:00 UTC of day D and 07:00 UTC of day D+1. In order to consider a correspondence between rain events and analysed fields, the analysis with the closest cyclone center to the Balearics (within a radius of $600 \mathrm{~km}$ ) was selected (Campins et al., 2006a). If any cyclone was located a distance higher than $600 \mathrm{~km}$, or even if no cyclone was detected, 12:00 UTC was selected as the representative for the $24 \mathrm{~h}$ interval.

Atmospheric patterns related to HR events were derived by using PCA and CA (Yarnal, 1993). First of all, the Tmode (day-by-day) correlation matrix was subjected to PCA for each parameter. Only the most important extracted components were considered, that is, by accounting at least the $90 \%$ of the total variance. Thus, 6 components were stored for geopotential at 1000 and for the temperature at $850 \mathrm{hPa}$ and 4 components for geopotential at $500 \mathrm{hPa}$. After that, the CA was applied to the total matrix of loadings (with 16 loadings) of the 157 events. The CA classifies objects (days in this case) in groups, whose elements are similar (in the sense of the PC loadings). In other words, days with similar loadings on the extracted components were clustered together. The clustering algorithm was the non-hierarchical $k$-means method (Anderberg, 1973). This algorithm minimizes the total (or sum of) intra group sum of squares $(W)$, and $W$ decreases as the number of groups $(k)$ increases. In this method the number of groups needs to be indentified before the algorithm proceeds. The optimal number of groups was selected when the decrease was not significant. In the present study the decrease of $W$ respect to $k$ was calculated for $k=2$ to $k=20$. Furthermore, to explore the possible number of groups, tree diagrams, obtained from hierarchical methods, were also examined.

\section{Results}

\subsection{HR Atmospheric Patterns}

Eight AP were obtained (hereafter AP1, AP2,...AP8). For each one, mean fields were obtained for parameters at different levels by averaging all the gridded analysis for the members of that AP. The following description is mainly based on the atmospheric fields, $\phi_{1000}, \phi_{500}$ and $T_{850}$, used to obtain the patterns (see Fig. 1). Furthermore, in order to deepen into the description of the AP, other fields as $850 \mathrm{hPa}$ geopotential height and the relative humidity at $925 \mathrm{hPa}$ and $850 \mathrm{hPa}$, were also considered (not shown here).

An aspect that must be taken into account is that each AP is an average of different atmospheric fields of the days classified in each cluster. Therefore each AP must be analysed bearing in mind that it is not a real atmospheric pattern, but an average of real ones.

AP1 is characterized by an intense low pressure centre close to Balearics at $1000 \mathrm{hPa}$, and a trough that extends from the Atlantic up to the Balearics at $500 \mathrm{hPa}$. A frontal wave in thermal and relative humidity fields at $850 \mathrm{hPa}$ is clearly suggested, which could induce a flow of wet and warm air over the islands.

Apart from AP5, the weakest cyclonic structure at $1000 \mathrm{hPa}$ for all of the patterns, is represented by the average of AP2. At $500 \mathrm{hPa}$ a weak trough over West Europe with a zonal flow over the Balearics can be outlined. The thermal field at $850 \mathrm{hPa}$ presents a warm ridge over the Iberian Peninsula, coinciding with low values of relative humidity. Over the Balearics a strong thermal gradient separates cold air at the North from warm air at the South. Moreover, a maritime low placed at the southwest edge of the Mediterranean that extends inland Spain is observed. This pattern occurs mainly in summer. In this season, the cyclones tend to be over land, concentrated in the Iberian Peninsula and Algeria, and Moroccan coast region (Campins et al., 2006b). AP2 is the most frequent of the patterns, with 26 events $(\approx 17 \%$ of the total events).

AP3 is characterized at low levels by an extended low pressure system that includes the Balearic Islands, the Gulf of Lyon and the Gulf of Genoa. The geopotencial field at upper levels shows a trough over the Iberian Peninsula, with a southwesterly flow over the Balearics. There is a cold 
AP1
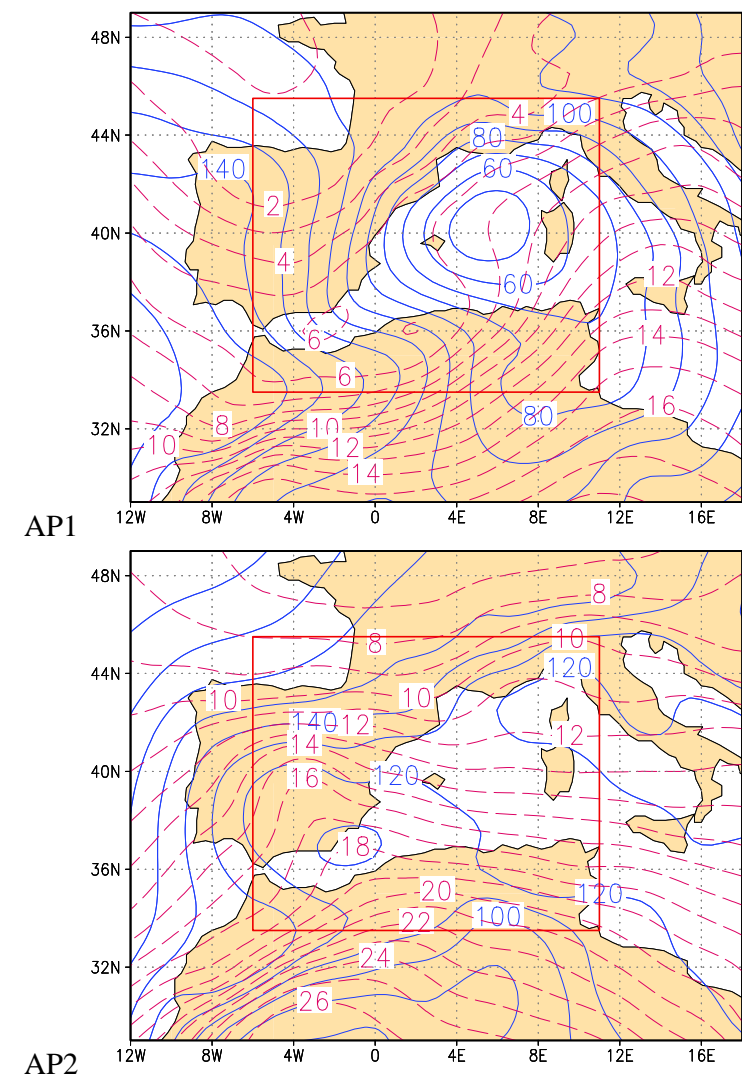

AP2

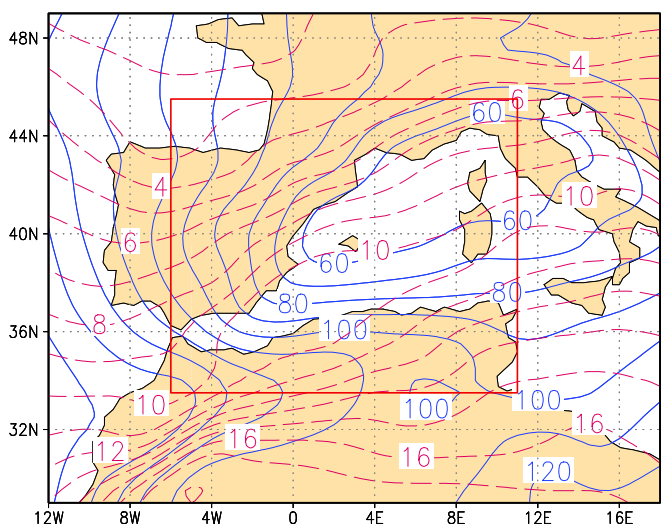

AP3

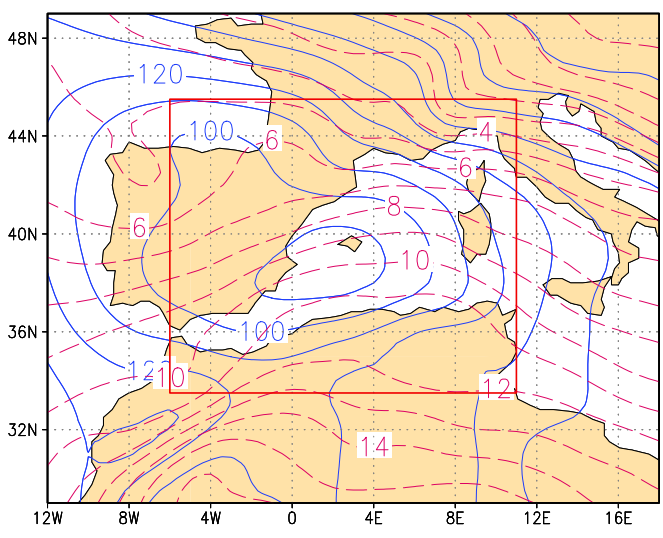

AP1
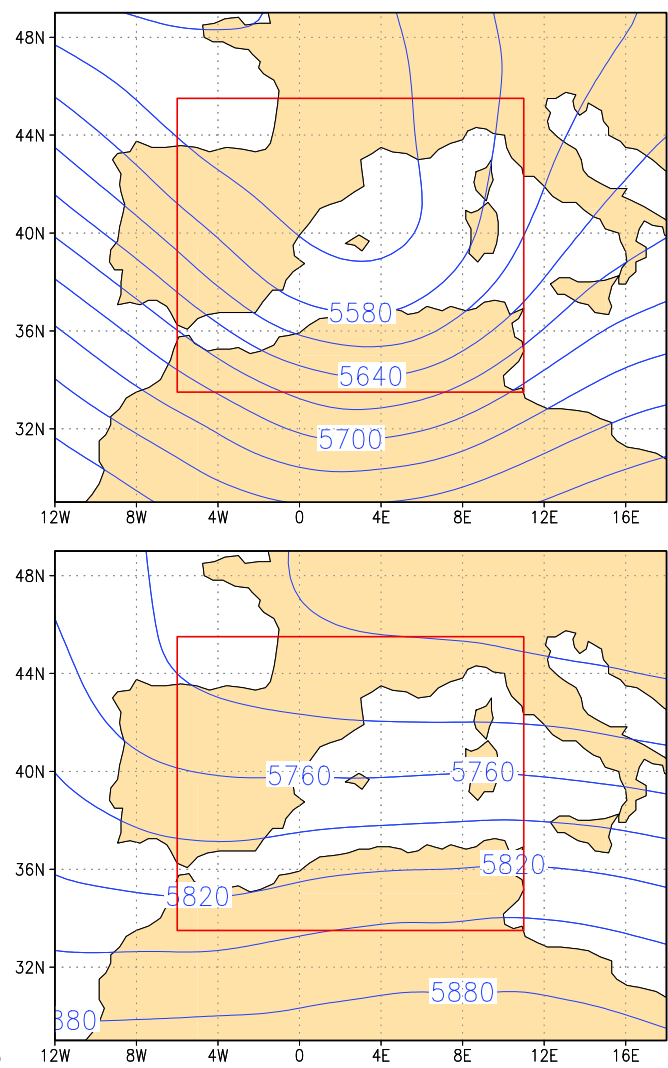

AP2

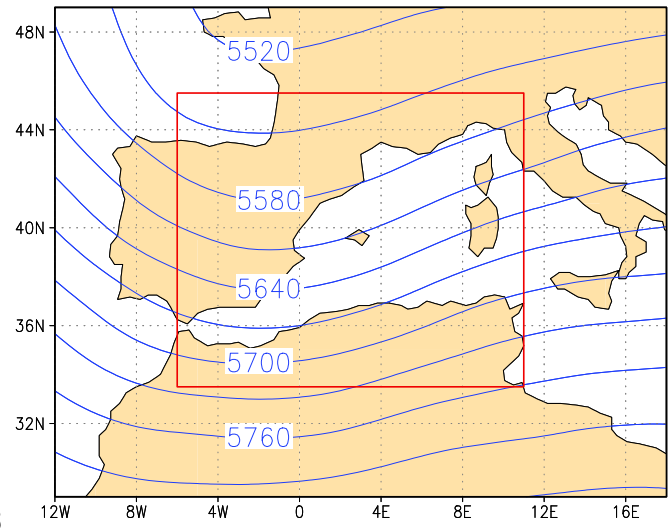

AP3

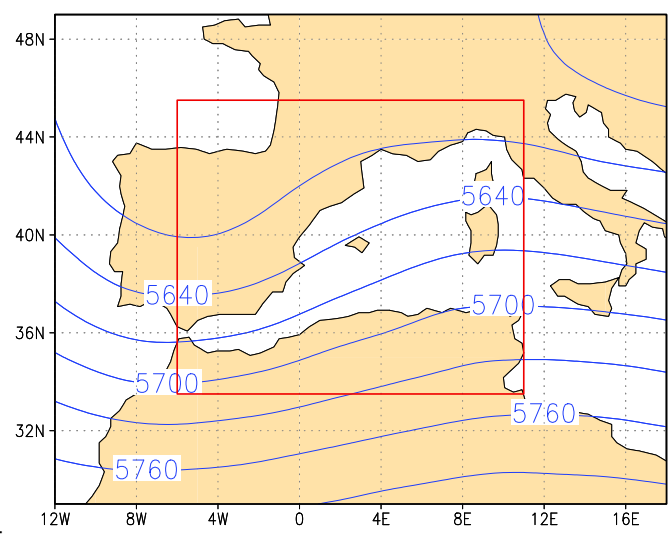

Fig. 1. Left panels: geopotencial at $1000 \mathrm{hPa}$ (blue solid lines, $10 \mathrm{gpm}$ ) and temperature at $850 \mathrm{hPa}$ (red dashed lines, $1^{\circ} \mathrm{C}$ ). Right panels: geopotencial at $500 \mathrm{hPa}$ (blue solid lines, $30 \mathrm{gpm}$ ) for AP1, AP2, AP3 and AP4. In solid red box the sudy domain where the classification was performed. 

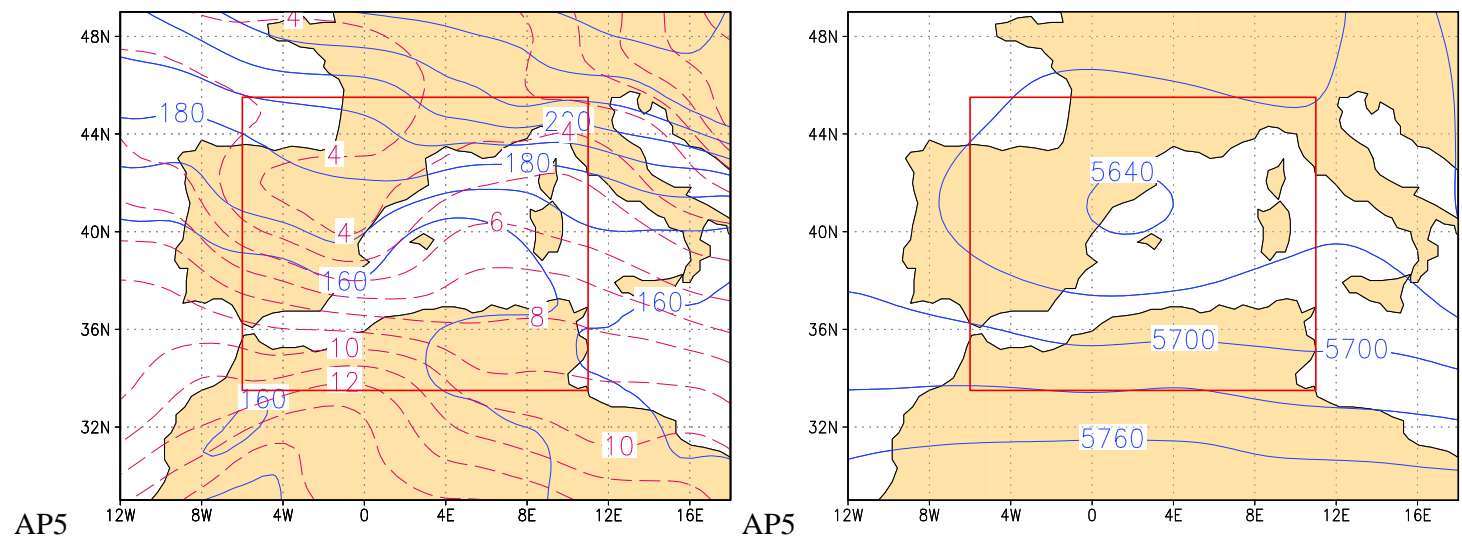

$\mathrm{AP} 5$

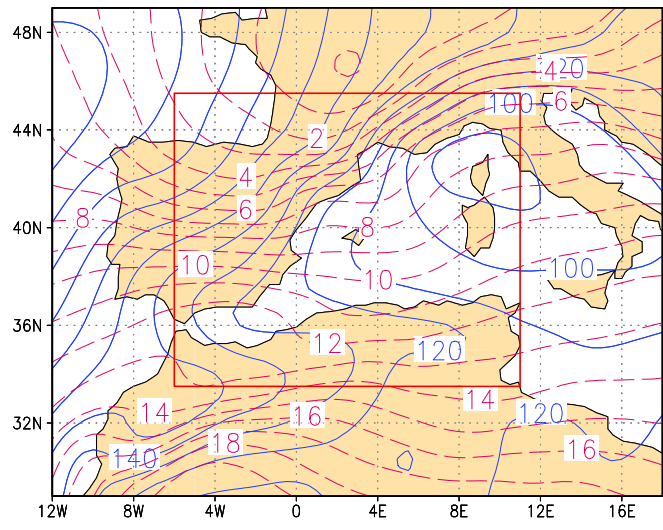

AP6

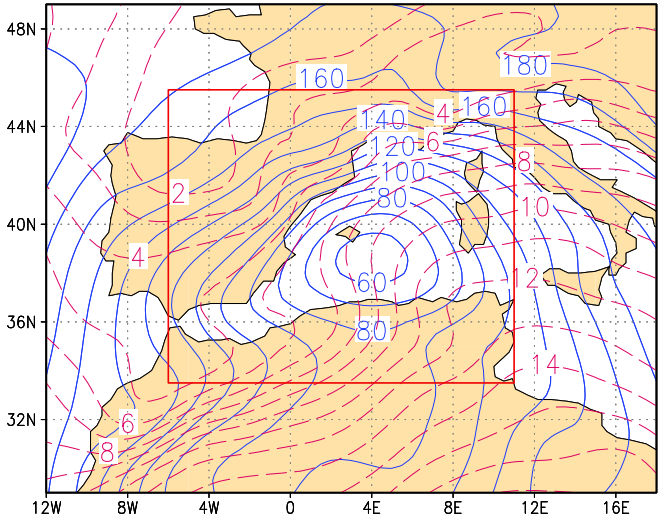

AP7

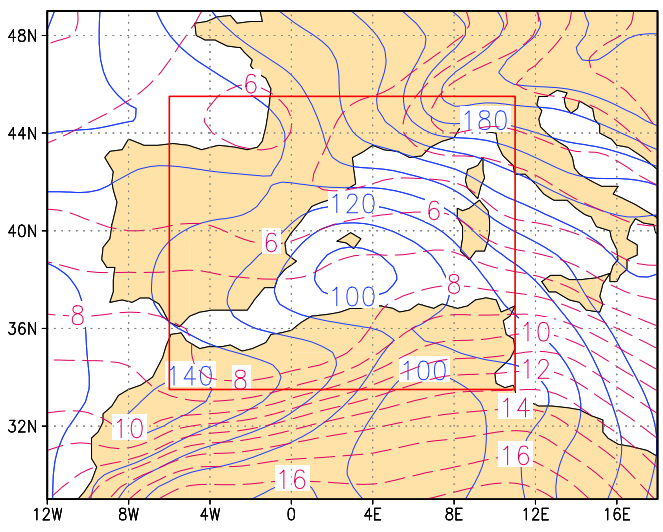

AP5

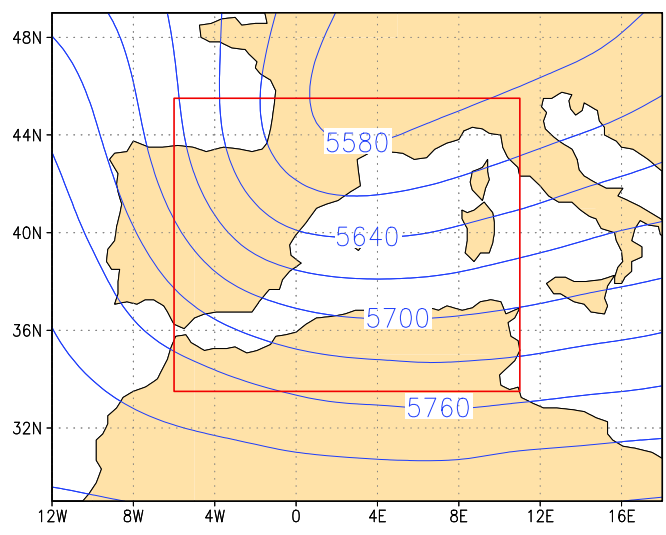

AP6

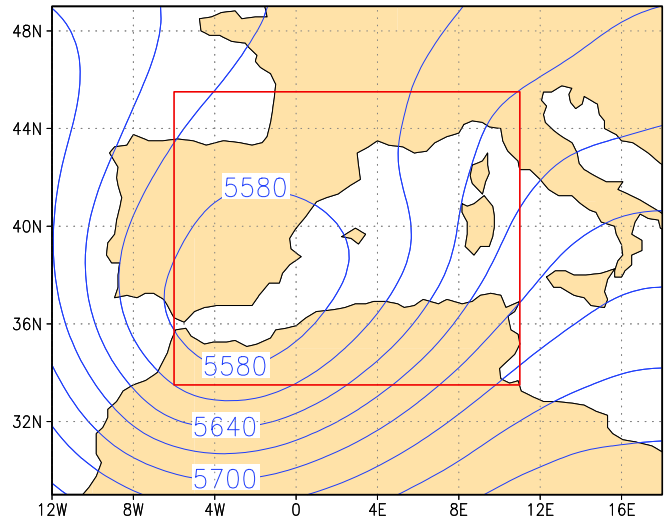

AP7

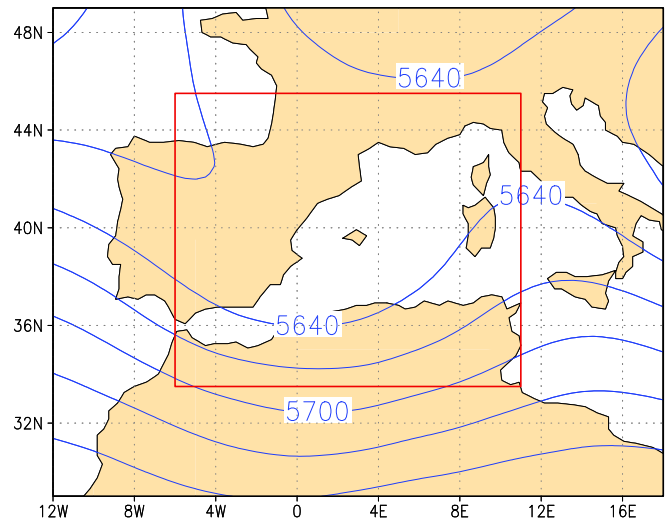

Fig. 1. Continued for AP5, AP6, AP7 and AP8. 
Table 2. Number of HR events for different intervals of maximum rainfall (in $\mathrm{mm} / 24 \mathrm{~h}$ ) and mean value of maximum rainfall $(\bar{x}(\mathrm{~mm}))$ for each AP and for the total set of events.

\begin{tabular}{ccccccc}
\hline AP & $60 \geq x \leq 80$ & $80<x \leq 100$ & $100<x \leq 150$ & $150<x \leq 200$ & $x>200$ & $\bar{x}(\mathrm{~mm})$ \\
\hline AP1 & 11 & 3 & 4 & 2 & 0 & 91 \\
AP2 & 12 & 7 & 5 & 2 & 0 & 92 \\
AP3 & 13 & 2 & 0 & 0 & 0 & 71 \\
AP4 & 9 & 8 & 3 & 1 & 0 & 89 \\
AP5 & 4 & 3 & 3 & 1 & 1 & 115 \\
AP6 & 16 & 6 & 2 & 1 & 0 & 81 \\
AP7 & 10 & 2 & 2 & 2 & 3 & 114 \\
AP8 & 11 & 3 & 4 & 1 & 0 & 87 \\
TOTAL & 86 & 34 & 23 & 10 & 4 & 91 \\
\hline
\end{tabular}

advection over Iberian Peninsula and a warm ridge over the islands. This warm air flows over the sea, so a large amount of moisture can contribute to the precipitation feeding.

There is a low pressure center in AP4, right next to the Balearics at low levels. At high levels this pattern is charaterized by a trough over the Iberian Peninsula that produces southwesterly flow over the Balearics. The temperature distribution exhibits a thermal ridge over the islands, that could bring warm flow to the archipelago from North Africa. At low levels, this pattern presents high values of relative humidity over the Balearics and hence the feeding of moisture to produce precipitation is guaranteed.

AP5 is the less frequent pattern, with only 12 events of heavy rain. At low levels, this pattern is characterized by a pressure trough and a warm ridge to the east of the islands. As a result, an easterly warm flow is induced over the sea, accounting for large values of humidity. At $500 \mathrm{hPa}$, a cutoff low just over the Balearic Islands is observed.

There is a cyclone at low levels in AP6, situated over the Gulf of Genoa, that induces cold advection from the North, reaching the Balearic Islands. At high levels, the presence of a trough that extends from France to the Iberian Peninsula favours the upward motion.

$\mathrm{AP7}$ presents a deep cyclone. At $1000 \mathrm{hPa}$, the cyclone is situated over the Balearics, it is very intense, and at $500 \mathrm{hPa}$ there is a cut-off situated in the southwest of the Balearics. This situation induces warm and moist air to the islands, as it is shown by the temperature field and the trayectory over the sea, which is an important factor for the generation of heavy rain events.

Pattern AP8 presents a cyclone over the Islands at low levels. At $500 \mathrm{hPa}$, there is a weak trough that covers the Balearic Islands. The temperature structure indicates no remarkable features, with a weak gradient over the Balearics.

\section{Discussion and further remarks}

In order to study the relationship between the patterns and the HR events, both the pluviometric histograms and the HR seasonal distribution were obtained for each pattern. Tables 1 and 2 show those distributions.

As Fig. 1 shows, the presence of a cyclone centre near the Balearics is observed in most of the AP. In six of them (AP1, AP3, AP4, AP6, AP7 and AP8) the cyclone is clearly associated with the HR events. Besides the presence of a cyclone, the $850 \mathrm{hPa}$ temperature field is quite similar for these patterns, with a warm ridge or a frontal structure, that could induce warm air to the islands. However, at $500 \mathrm{hPa}$ there is a wide variety of atmospheric structures. On the one hand, in AP1 and AP8, the trough extends from the Atlantic Ocean up to the Balearics. On the other, the trough extends from the West of Europe, over the Iberian Peninsula in patterns AP3, AP4 and AP6. Finally, AP5 and AP7 show a cut-off at upper levels. Moreover AP7 is a very rainy one, with a mean maximun precipitation of $114 \mathrm{~mm}$ per day, and as it was expected, almost all of the cases of this pattern are in autumn.

In summary, in spite of the differences between patterns, a general scenario for heavy rain in the Balearics can be described: at low levels an intense cyclone drives warm and moist air towards the islands, which ascent is usually favoured at upper-levels.

There are two patterns with a weak cyclone at low levels that deserve special attention: AP2 and AP5.

As mentioned in the previous section, AP2 at $500 \mathrm{hPa}$ presents a zonal flow over the Balearics and a weak trough over the West Europe. When a deeper analysis of some particular cases is performed, a short-wave trough, embeded into the mean flow can be found (which is smoothed in the mean field). This short-wave trough is accompained with a cold air intrusion to the Mediterranean through the gulf of Lyon, which could act as a trigger mechanism. As many of these events are registered in August and first days of September, these condicions are able to produce local convection. In fact, for most of these events HR was recorded in just one point. 
AP5, unlike the other patterns, is not always associated with a cyclone at low levels. However, as Table 2 shows, this pattern is the most rainy one. As it has been mentioned, the low level circulation is characterized by a warm easterly flow that ensures the continous feeding of moist air. In addition, the presence of a cut-off at high levels favours the lifting of the air. These conditions finally contribute to the great efficiency of precipitation.

\section{Conclusions}

Eight atmospheric patterns have been obtained to explain the heavy rain events in the Balearic Islands. In spite of the fact that the patterns do not correspond to real atmospheric configurations, being obtained by averaging real fields, most of them reproduce the presence of a cyclonic structure at low levels, close to the rain affected region.

Two main groups can be distinguish according to the intensity of such a cyclone. For most of the patterns, the presence of an intense or moderate cyclone at low levels and the configuration at upper levels can consistently explain the occurrence of rain. Only in two cases (AP2 and AP5) the cyclone is weak or not clearly present at low levels, although a weak cyclonic circulation is always suggested. AP5, the most rainy atmospheric pattern, presents a cut-off at upper levels, consistent with the presence of heavy rain. The zonal configuration at high levels and the weak cyclonic circulation at low levels for AP2 renders the HR mechanism not evident, but the great number of members belonging to this pattern produces a smoothing of small scale features.

The atmospheric patterns could explain the heavy rain events of the Balearic Islands and could be a helpful tool for the improvement of the forecast of these severe weather events.
Acknowledgements. The authors wish to thank M. A. Picornell for her helpful comments. This work has been partially funded by the CICYT CGL2005-05681/CLI grant.

Edited by: P. Alpert, H. Saaroni, and E. Heifetz

Reviewed by: two anonymous referees

\section{References}

Anderberg, M. R.: Cluster Analysis for Applications, Academic Press, New York, 1973.

Campins, J., Jansà , A., and Genovés, A.: Heavy rain and strong wind events and cyclones in the Balearics, Adv. Geosci., 7, 7377, 2006, http://www.adv-geosci.net/7/73/2006/.

Campins, J., Jansà, A., and Genovés, A.: Three-dimensional structure of Western Mediterranean cyclones, Int. J. Climatol., 26, 323-343, 2006.

Houssos, E. and Bartzokas, A.: Extreme precipitation events in NW Greece, Adv. Geosci., 7, 91-96, 2006, http://www.adv-geosci.net/7/91/2006/.

Jansà, A., Genovés, A., and García-Moya, J. A.: Western Mediterranean cyclones and heavy rain. Part I: Numerical experiment concerning the Piedmont flood case, Meteorol. Appl., 7, 323333, 2000.

Jansà, A., Genovés, A., Picornell, M. A., Campins, J., Riosalido, R., and Carretero, O.: Western Mediterranean cyclones and heavy rain. Part II: Statistical approach, Meteorol. Appl., 8, 43-56, 2001.

Romero, R., Sumner, G., Ramis, C., and Genovés, A.: A classication fo the atmospheric circulation patterns producing significant daily rainfall in the Spanish Mediterranean area, Int. J. Climatol., 19, 765-785, 1999.

Yarnal, B.: Synoptic Climatology in Environmental Analysis, Belhaven Press, London, 1993. 